\title{
DEVELOPMENT AND CONSTRUCTION OF AN INSTRUMENTED WORKBENCH FOR CHARACTERIZATION OF HYDRAULIC MOTORS
}

\author{
Luís Carlos Wachholz \\ Horizontina, Rio Grande do Sul, Brazil
}

\author{
Antonio Carlos Valdiero \\ Panambi, Rio Grande do Sul, Brazil
}

\author{
Luiz Antônio Rasia \\ Panambi, Rio Grande do Sul, Brazil
}

\begin{abstract}
This work addresses the design and construction of an instrumented workbench for characterization tests of hydraulic motors. The main objective is the workbench construction for future characterization of a gerotor hydraulic motor with proportional directional valve. The gerotor hydraulic motor has as advantage to work in a situation of low rotation and high torque. The workbench must be able to identify the characteristic parameters of the dynamic model, besides the elaboration of experimental curves involving flow, pressure, rotation and torque, depending on the variation of the applied load. The workbench basically consists of a gerotor hydraulic motor, proportional valves, valve amplifier, sensors and a hydraulic power unit. The mathematical modeling of hydraulic system involved in this motor drive provides valve spool dynamics, dead zone non-linearity, valve orifice flow, pressures dynamics, static and dynamic friction and angular movement dynamics. The mathematical modeling of dynamic systems is important in machine design, because it allows predicting problems and opportunities for optimization of constructive parameters through computational simulations, which, together with experimental laboratory practices, allow the validation of the behavior of its variables in machine and equipment prototypes in conditions similar to those found in the field. Considering the experimental data to be obtained from the workbench, simulating the real operating conditions and the dynamic modeling, it will allow us a systematic analysis of the rotation, torque and pressure behavior, which allows to properly size the input parameters, identify critical points of and propose solutions. This workbench will contribute to the research and development of innovative technologies for use in proportional hydraulic systems, facilitating rotation and torque control and optimizing energy use.
\end{abstract}

Keywords: Gerotor hydraulic motor, instrumented workbench, proportional valve, characteristic curves.

\section{INTRODUCTION}

The identification of the characteristic parameters of the dynamic model of a hydraulic motor through mathematical modeling allows to know adequately the relationships between them, allowing the elaboration of characteristic curves such as torque versus rpm, pressure drop versus flow, pressure versus rpm and curves involving three or more parameters for its identification, as the efficiency of the system. The validation of these models will be through practical experimentation with the use of this instrumented workbench.

For a better characterization of these parameters, it is necessary to use a proportional directional valve which is directly controlled by two solenoids, with a spring-centered central position and a spool position transducer. The operation of this type of valve requires an electronic controller/amplifier that receives both the external reference signal and the feedback signal from the position transducer, processes them and sends electrical signals to the solenoids [1].

Proportional electro-hydraulic directional valves are widely used in most pressure and flow control applications for industrial or mobile hydraulic systems [2]. Hydraulic systems have been widely applied in engineering machinery, metallurgy and extrusion equipment, due to its high power / weight ratio and high rigidity. Especially, when the hydraulic system drives the high-power load, the advantages of small volume and stable performance are highlighted [3].

The engine will be of the gerotor type consisting of a set of gears, an internal gear that rotates and orbits in contact with an external gear. These motors are suitable for delivering high torque at low speed. The internal gear rotates a $n$ times for each revolution of the cardan shaft. For this reason, the inherent volumetric displacement of the unit will be $n$ times larger than that of existing pumps and gear motors [4]. The use of these motors with the respective control of the hydraulic system, applied in machines and equipment, is one of the directions of the development of high technology in industrial applications. It is because of its outstanding features such as compact structure, large torque transmission, fast response speed, self-lubricating and heat transfer properties in liquid and good system life that are used in industrial and mobile machinery. The volumetric and mechanical efficiency of these engines has been widely referenced in terms of volumetric and torque losses, in which a proposed analytical model [6] of a generalized equation relating the general 
efficiency to the pressure and angular velocity for pumps and motors and showing how the model can be adjusted to real experimental data.

The high temperature of the hydraulic fluid implicate the overall efficiency of the entire system, requiring its monitoring and prescription a model capable of predicting the working temperature of the hydraulic fluid in the casing volume and in the outlet port. The working temperature is estimated [7] considering the power losses associated with the fluid flow at the lubrication interfaces, the agitating movement of the oil in the machine housing and the losses due to the compressibility of the hydraulic fluid.

Technological trends and the impact on existing pump and motor designs used in actuators controlled by displacement, continuously variable transmissions and hydraulic hybrid powertrains [8] allow for large fuel savings and emission reductions, but change the positive displacement of pump and motor performance requirements. The main challenges of these trends are related to efficiency improvements, noise reduction and advances in the control of pumps and motors.

\section{OBJECTIVES}

The main objective is the design and construction of a workbench for characterization of a gerotor hydraulic motor with proportional directional valve, in situation of low rotation and high torque, through the identification of the characteristic parameters of the dynamic model.

As specific objectives of this work we can cite:

- Allow the easy characterization of commercial hydraulics motors comparing it with the information available in the manufacturer's catalogs;

- Allow to identify the parameters of mathematical modeling suitable for the representation of the dynamic behavior of the friction and temperatures, and the inclusion of the main nonlinearities.

- Allow perform experimental validation tests of the proposal of mathematical modeling and control of the drive of the hydraulic motor, including the analysis of the obtained results.

\section{DESIGN OF THE EXPERIMENTAL WORKBENCH}

The conceptual design is the part of the design process where the techniques of creativity, the elaboration of function structures, the search for principles of solution, their combinations in the synthesis of conceptions and the techniques of evaluation are applied with the purpose of reaching a conceptual solution that is possible to solving the problem [9].

For the development of the workbench, the resources and equipment available were used in the Center of Innovation in Automatic Machines and Servo Systems (NIMASS) at Regional University of the Northwest of Rio Grande do Sul State.

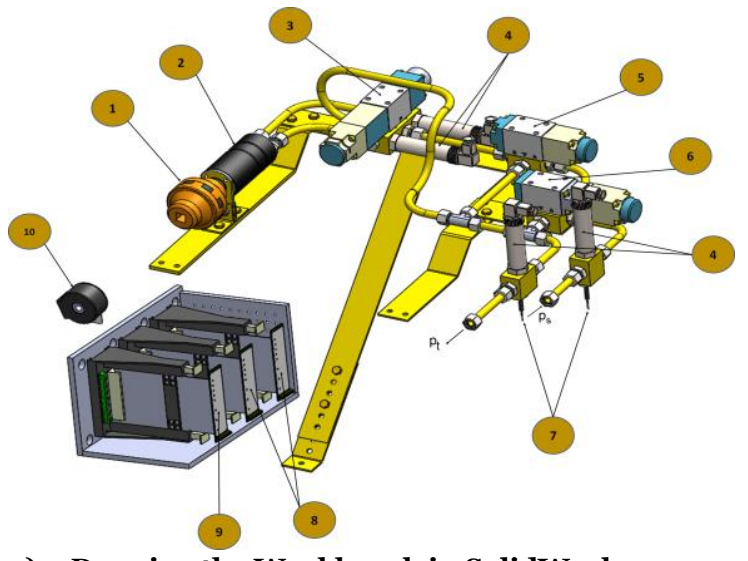

a) Drawing the Workbench in SolidWorks

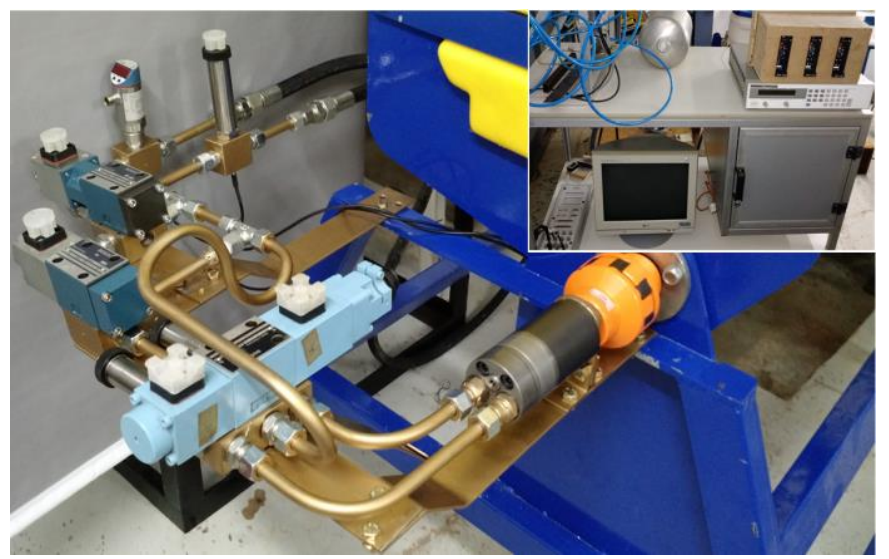

b) Image of the bench already mounted Figure 1 - Instrumented workbench for characterization tests of hydraulic motors.

The main workbench components are shown in Figure 1a and $1 \mathrm{~b}$. The hydraulic power (pressure and flow) will be used of a hydraulic power unit available in NIMASS, but not shown in the figure, will be used, which has pressure and flow control through valves and hydraulic oil temperature through a cooler.

Flow rate and pressure control of the hydraulic system will be controlled directly through the flow and pressure proportional valves. The control of the hydraulic motor rotation will be carried out through computerized software 
connected to the electronic system of the proportional valves. The workbench sensors will also be connected to the software providing in real time the data required for the experimental tests and allowing comparison with the data of the computer simulation through the mathematical models.

The test rig used for the purpose of investing in the determination of the characteristic parameters in hydraulics valves and motors according with what is depicted in Figure 1, it is formed by one acquisition and control system mounted in a PC microcomputer and one hydraulic system, that is composed by one proportional directional valve (3), one proportional flow valve (5) and one proportional pressure valve (6). Sensors (4) permit measure hydraulic system inlet (ps) and outlet (pt) pressure, inlet (pa) and outlet (pb) pressure in the hydraulic motor and speed of the hydraulic motor. For the acquisition and control system used is a dSPACE DS 1102 board which control the amplifiers signals (8) e (9).

In Figure 2, is cited the proposed hydraulic scheme for the hydraulic motor drive. It includes the power unit, the three proportional valves (directional, pressure and flow), hydraulic motor, drive shaft, hydraulic connections and sensors.

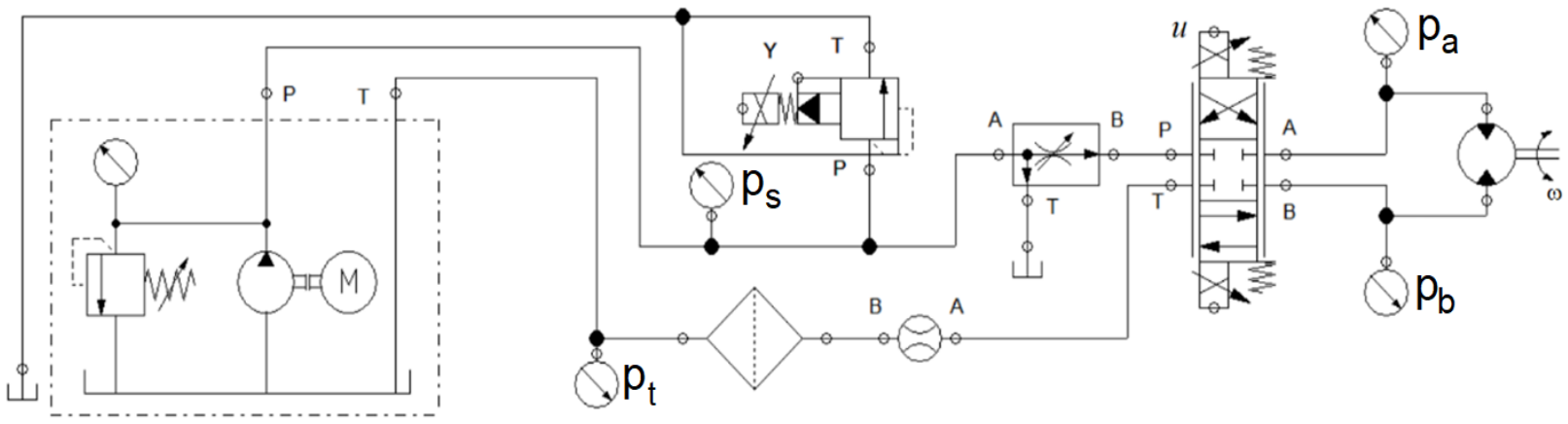

Figure 2 - Hydraulic workbench layout according to ISO 1219

The validation of the dead-zone mathematical modeling, the friction dynamics [10] and the flow dynamics in the proportional directional valve holes, the dynamics of the pressures in the chambers [11] and the axis movements in the hydraulic motor, as depicted in Figure 3.

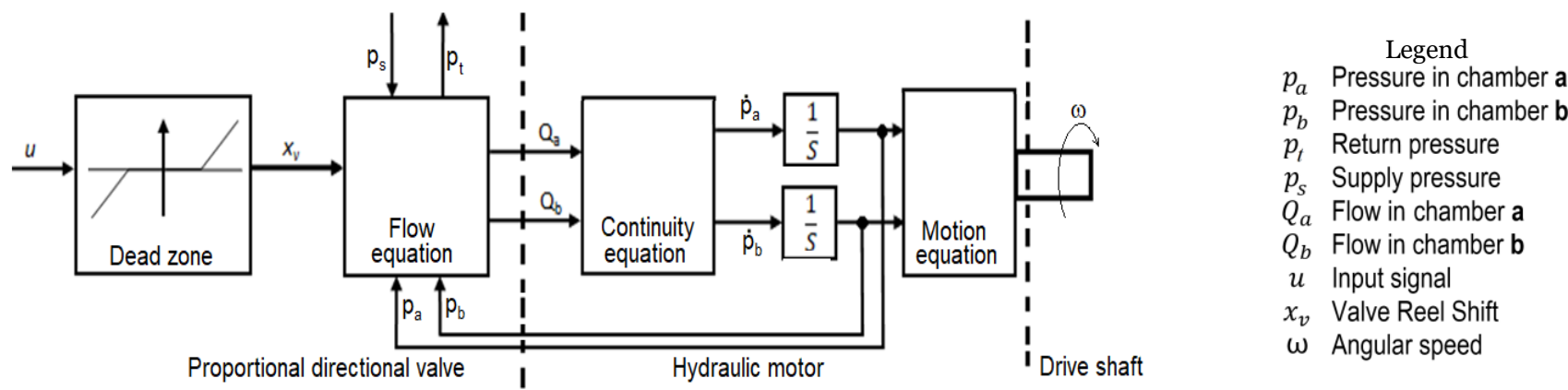

Figure 3: Functional Diagram of workbench with hydraulic system variables

The dead zone of a proportional directional valve is a static input-output relationship in which there is no output for a range of input values [10]. Figure $4 \mathbf{a}$ shows a graphical representation of the dead zone where $\boldsymbol{u}$ is the input signal, $\boldsymbol{u}_{\boldsymbol{z} \boldsymbol{m}}$ is the output value, $\mathbf{z m \boldsymbol { d }}$ is the right edge of the dead zone, zme the left value of the dead zone, $\boldsymbol{m \boldsymbol { d }}$ is the right slope of the dead zone, and $\boldsymbol{m} \boldsymbol{e}$ is the left slope of the dead zone.

The dead zone analytical expression is given by Eq. 1 .

$$
u_{z m}(t)=\left\{\begin{array}{cl}
m d(u(t)-z m d) & \text { se } u(t) \geq z m d \\
0 & \text { se } z m e<u(t)<z m d \\
m e(u(t)-z m e) & \text { se } u(t) \leq z m e
\end{array}\right\}
$$




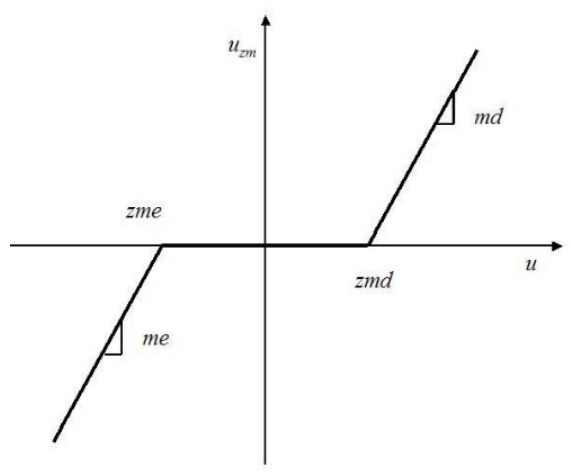

(a)

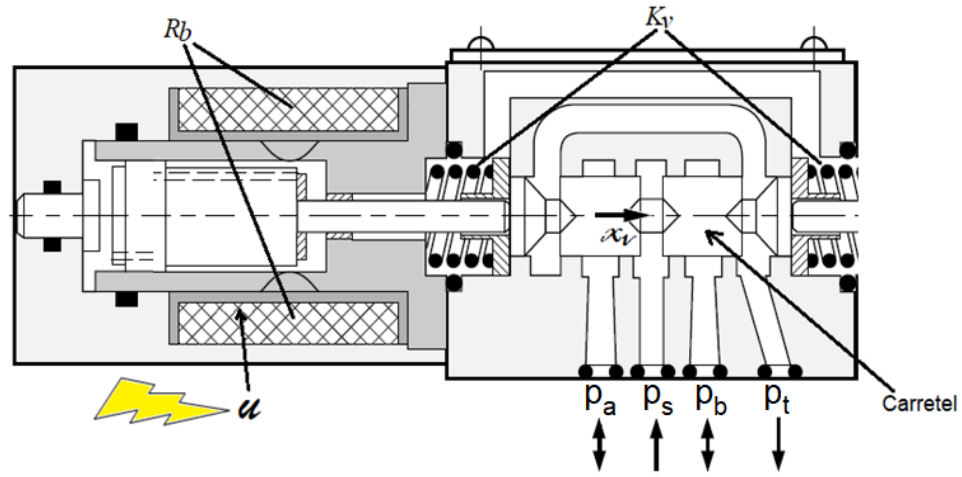

(b)

Figure 4 - Parameters characteristic of the directional valve: (a) Graphical representation of the dead zone and (b) schematic drawing of a proportional directional valve.

The determination of the flows in the proportional directional valve holes through the displacement $\boldsymbol{x}_{v}$, decipted schematically in Figure 4b, can be done from the Bernoulli equation [13] resulting in Eqs. 2 and 3.

$$
\begin{array}{r}
Q_{a}\left(x_{v}, p_{a}\right)=\begin{array}{ll}
k_{s} \cdot x_{v} \cdot \sqrt{p_{s}-p_{a}} & \text { para } x_{v} \geq 0 \\
k_{s} \cdot x_{v} \cdot \sqrt{p_{a}-p_{t}} & \text { para } x_{v}<0
\end{array} \\
Q_{b}\left(x_{v}, p_{b}\right)=\begin{array}{ll}
k_{s} \cdot x_{v} \cdot \sqrt{p_{b}-p_{t}} & \text { para } x_{v} \geq 0 \\
k_{s} \cdot x_{v} \cdot \sqrt{p_{s}-p_{b}} & \text { para } x_{v}<0
\end{array}
\end{array}
$$

The relation between the areas of the control holes is equal to the ratio between the cross-sections of the chambers of the differential cylinder, when displacing the spool from a distance $\boldsymbol{x}_{\boldsymbol{v}}$, flow rates can be calculated which can be calculated through Bernoulli Equation, where, $\boldsymbol{Q}_{\boldsymbol{a}}\left(\boldsymbol{x}_{\boldsymbol{v}}, \boldsymbol{p}_{\boldsymbol{a}}\right)$ and $\boldsymbol{Q}_{\boldsymbol{b}}\left(\boldsymbol{x}_{\boldsymbol{v}}, \boldsymbol{p}_{\boldsymbol{b}}\right)$ are the inlet and outlet flow rates, $\boldsymbol{k}_{\boldsymbol{s}}$ is the flow coefficient of the valve chamber $\boldsymbol{a}$ and $\boldsymbol{b}, \boldsymbol{x}_{\boldsymbol{v}}$ is the valve spool displacement, $\boldsymbol{p}_{\boldsymbol{s}}$ is the supply pressure, $\boldsymbol{p}_{\boldsymbol{t}}$ is the return pressure, $\boldsymbol{p}_{\boldsymbol{a}}$ and $\boldsymbol{p}_{\boldsymbol{b}}$ are the pressures in chambers $\boldsymbol{a}$ and $\boldsymbol{b}$ of the hydraulic motor, respectively.

The model of hydraulic motor of the gerotor type that will be used will be of the brand Danfoss OMM 50. The description of the mathematical model of the hydraulic motor follows the hypothesis, in this case, that the motor will be unidirectional, in which the fluid flow will enter the chamber $\boldsymbol{a}$ and will exit through chamber $\boldsymbol{b}$, as shown in Figure $5 \mathbf{a}$.

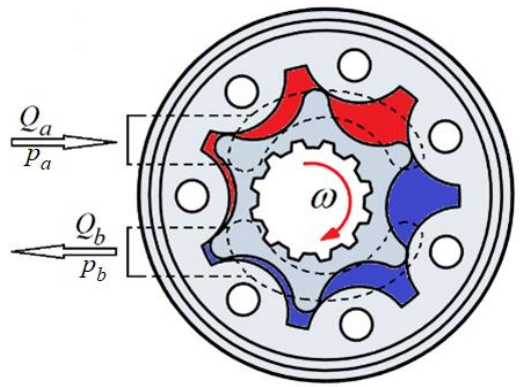

(a)

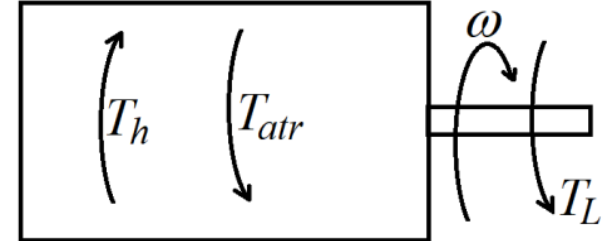

(b)

Figure 5 - Parameters characteristic of the hydraulic motor (a) Diagram of the operation of the hydraulic motor gerotor type and (b) Torques in the hydraulic motor.

Initially it is necessary to derive the motor continuity equation for one chamber and ends in the differential pressure equation as a time function for the equations of the chambers $\boldsymbol{a}$ and $\boldsymbol{b}$, according to Eqs. 4 and 5 .

$$
\begin{aligned}
& \frac{d p_{a}}{d t}=\frac{\beta}{V_{a}}\left(Q_{a}-D . \omega\right) \\
& \frac{d p_{b}}{d t}=\frac{\beta}{V_{b}}\left(D . \omega-Q_{b}\right)
\end{aligned}
$$


Consider the schematic of a hydraulic motor with what is depicted in Figure $5 \mathbf{b}$, the shaft is responsible for transmitting the rotation of the hydraulic motor to the drive shaft. The modeling of the drive shaft will be based on the torque that the hydraulic motor must have to overcome the load torque and the reactions that will occur in the form of friction torque. According to Eq. 6, the drive of the shaft is performed by a torque of the hydraulic motor $\boldsymbol{T}_{\boldsymbol{h}}=\boldsymbol{D}$. $\left(\boldsymbol{p}_{\boldsymbol{a}}-\boldsymbol{p}_{\boldsymbol{b}}\right)$ which generates a reaction that is contrary to the movement due to the friction caused by the rolling bearings or bushings of the motor, friction between the internal gears of the gerotor and the viscosity of the fluid, called the friction torque $\boldsymbol{T}_{\boldsymbol{a t r}}(\boldsymbol{\omega})$ and the torque related to the load that must move $\boldsymbol{T}_{\boldsymbol{L}} . \boldsymbol{D}$ is the volumetric displacement of the hydraulic motor. The torque unit is in N.m.

$$
I_{e q .} \dot{\omega}+T_{a t r(\omega)}=D .\left(p_{a}-p_{b}\right)-T_{L}
$$

Friction is generally described as the resistance to movement of two surfaces in contact that affect or deteriorate performance and impair movement. Friction is the force contrary to movement and its characteristics are always present in the interaction between mechanical mechanisms [14]. For the study of the dynamics of the movement, the effect of the friction will be considered to compensate or to reduce its effects.

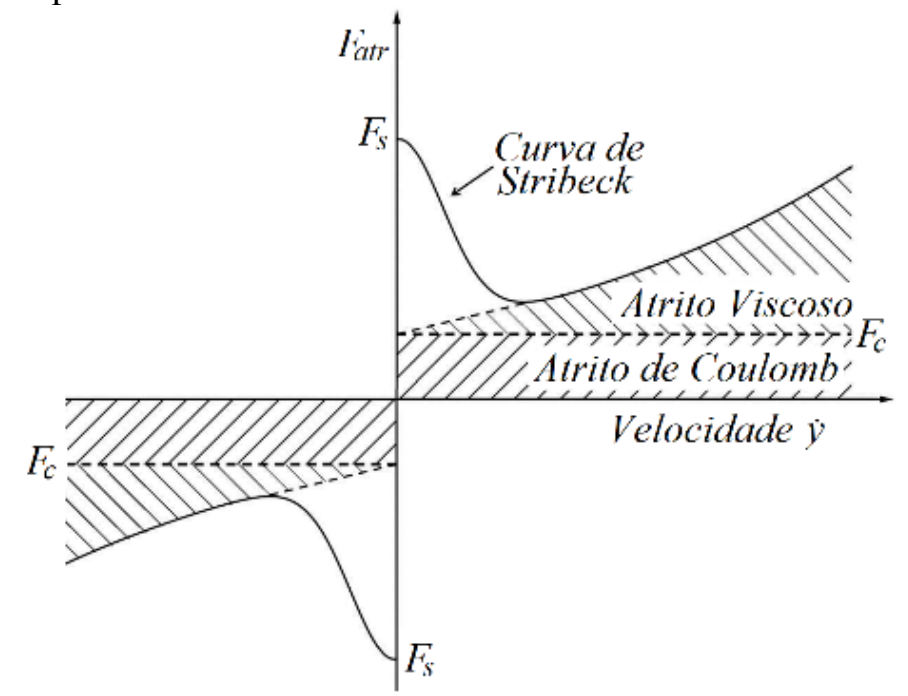

Figure 6 - Graph of the combination of permanent friction characteristics

Figure 6 presents, through a graph, some of the characteristics cited and used for the modeling of the friction dynamics in steady state according to Eq.7 [12].

$$
T_{a t r}(\omega)=T_{c}+\left(T_{s}-T_{c}\right) e^{-\left(\frac{\omega}{\omega_{s}}\right)^{2}}+B \cdot \omega
$$

Where $\boldsymbol{T}_{\boldsymbol{a t r}}(\boldsymbol{\omega})$ is the friction torque as a function of the angular velocity, $\boldsymbol{T}_{\boldsymbol{c}}$ is the Coulomb friction torque, $\boldsymbol{T}_{s}$ is the static friction torque, $\boldsymbol{\omega}_{\boldsymbol{s}}$ is the Stribeck velocity, $\boldsymbol{\omega}$ is the relative velocity between the two surfaces and $\boldsymbol{B}$ is the viscous friction coefficient.

The main characteristic parameters that the workbench is able to identify with regard to mathematical modeling are listed below.

zmd - Right edge of the dead zone,

zme - Left value of the dead zone

$Q_{a}\left(x_{v}, p_{a}\right)$ - Inlet flow rates

$Q_{b}\left(x_{v}, p_{b}\right)$ - Outlet flow rates,

$k_{s}$ - Flow coefficient of the valve chamber $\boldsymbol{a}$ and $\boldsymbol{b}$,

$T_{h}$ - Torque of the hydraulic motor

$T_{a t r}(\omega)$ - Friction torque as a function of the angular velocity,

$T_{c}$ - Coulomb friction torque,

$T_{s}$ - Static friction torque,

$\omega_{s}$ - Stribeck velocity,

$B-$ Viscous friction coefficient 


\section{CONCLUSION}

The design and construction of this workbench is important to characterize hydraulic motors by comparing them with the commercial characteristics through the experimental tests, besides validating the mathematical model of the valve and hydraulic motor dynamics. The results of these practical tests and the simulations will be published in form of publications in congresses and scientific journals of national and international recognition.

\section{ACKNOWLEDGMENTS}

This work has the financial support of CNPq (Conselho Nacional de Desenvolvimento Científico e Tecnológico National Council for Scientific and Technological Development) Brazilian governmental agency. Authors also wish to express gratitude to FINEP, FAPERGS and UNIJUÍ.

\section{REFERENCES}

[1] Totten, G. E.; De Negri, V. J. . "Handbook of Hydraulic Fluid Technology", Second Edition. 2. ed. Boca Raton, Florida: CRC Press - Taylor \& Francis Group, 2011.

[2] Liu, F.; Peng X. On Application of Proportional Valve-Controlled Hydraulic Cylinder Position Servo System. Proceedings of the 34th Chinese Control Conference, 2015. Hangzhou, China.

[3] Tao, T. An Electro-Hydraulic Control System with Energy Recycling. Natural Science Foundation of Beijing - China. 2015.

[4] Furustig, J. Et al. A wear model for EHL contacts in gerotor type hydraulic motors, Journal of Mechanical Engineering Science, 2015, Vol. 229(2) 254-264.

[5] Tran, N. H., Le, C., Ngo, A. D. Experimental Investigation of Speed Control of Hydraulic Motor Using Proportional Valve. International Conference on System Science and Engineering (ICSSE), 2017.

[6] Costa, G. K., Sepehri N. Understanding overall efficiency of hydrostatic pumps and motors. International Journal of Fluid Power. 2018. doi.org/10.1080/14399776.2018.1476306.

[7] Zecchi, M. Mehdizadeh, A. Ivantysynova, M. A novel approach to predict the steady state temperature in ports and case of swash plate type axial piston machines. The 13th Scandinavian International Conference on Fluid Power, SICFP2013, June 3-5, 2013, Linköping, Sweden.

[8] Ivantysynova, M. Innovations in Pump Design - What are future directions? Proceedings of the 7th JFPS International Symposium on Fluid Power, Toyama 2008.

[9] Pahl, G. and Beitz, W. "Engineering design: a systematic approach", London: The Design Council, 99.

[10] Valdiero, A. C., Guenther, R., Negri, V. J. New methodology for identification of the dead zone in proportional directional hydraulic valves. ABCM Symposium Series in Mechatronics. 1ed.Rio de Janeiro: ABCM Associação Brasileira de Engenharia e Ciências Mecânicas, 2006, v. 2, p. 377-384.

[11] Kumar, S., et al. Dynamic analysis of a hydro-motor drive system using priority valve. Journal of Process Mechanical Engineering, 2018. DOI: 10.1177/0954408918770470.

[12] Tao, G.; Kokotovic. P.V. Adaptive control of systems with actuator and sensor nonlinearities. Wiley. (1996).

[13] Valdiero, A. C. Modelagem Matemática de Robôs Hidráulicos. Ijuí: Ed. Unijuí, 2012.

[14] Linsingen, l. V. Fundamentos de Sistemas Hidráulicos. 5 ed. Florianópolis: UFSC, 2016. 